\title{
Avaliação da atividade antibacteriana e triagem fitoquímica das flores de Acacia podalyriifolia A. Cunn. ex G. Don Leguminosae-Mimosoideae
}

\author{
C.A. Andrade, C. Peitz, M. Cúnico, J.L.S. Carvalho, W.M. Abrahão, O.G. Miguel, M.D. \\ Miguel, V.A. Kerber*
} Programa de Pós Graduação em Ciências Farmacêuticas, Universidade Federal do Paraná,
Av. Lothário Meissner 3400, 80210-170, Curitiba, PR, Brasil

\begin{abstract}
RESUMO: A atividade antibacteriana das flores da Acacia podalyriifolia A. Cunn. (Leguminosae) foi avaliada pelo método de difusão em disco. As bactérias testadas foram: Staphylococcus aureus (ATCC 6538), Staphylococcus epidermidis (ATCC 1228), Escherichia coli (ATCC 11229) e Pseudomonas aeruginosa (ATCC 27853). O meio de cultura utilizado foi ágar Müeller-Hinton. Foram utilizados discos de papel (6 mm de diâmetro) impregnados com 1000, 500, 250 e 125 $\mu \mathrm{g}$ dos extratos: Etanol Bruto, fração Acetato de Etila e fração Diclorometano obtidas a partir do extrato etanólico bruto. Os resultados indicam que as amostras avaliadas exercem ação contra as cepas gram positivo testadas, em graus variáveis sendo que a fração Acetato de Etila apresentou maior atividade. A triagem fitoquímica indicou a presença de fenóis e flavonoides nas flores de $A$. podalyriifolia.
\end{abstract}

Unitermos: Acacia podalyriifolia, atividade antibacteriana.

\begin{abstract}
Evaluation of the antibacterial activity and phytochemical screening of the flowers of Acacia podalyriifolia A. Cunn. ex G. Don Leguminosae-Mimosoideae". The antibacterial activity of the flowers of Acacia podalyriifolia A. Cunn. (Leguminosae) was evaluated through the gel diffusion method. The bacteria tested were: Staphylococcus aureus (ATCC 6538), Staphylococcus epidermidis (ATCC 1228), Escherichia coli (ATCC 11229) and Pseudomonas aeruginosa (ATCC 27853). The culture media was agar Müeller-Hinton. Paper discs $(6 \mathrm{~mm}$ in diameter) with 1000, 500, $250 \mathrm{e} 125 \mu \mathrm{g}$ of the tested extracts (crude ethanolic and its fractions; Ethyl Acetate and Dichloromethane) were used. The results indicated action against the gram-positive tested strains in different levels. The Ethyl Acetate extract showed a higher activity. Phenols and flavonoids were detected in the flowers of A. podalyriifolia through phytochemical screening.
\end{abstract}

Keywords: Acacia podalyriifolia, antibacterial activity.

\section{INTRODUÇÃO}

Também conhecida como Acacia-mimosa, Acacia podalyriifolia A. Cunn. (Leguminosae) é uma planta exótica, originária da Austrália, vastamente difundida no sul do Brasil pelo cultivo como planta ornamental (Burkart, 1979). Apresenta-se como árvore pequena, atingindo no máximo 5 metros de altura.

Tradicionalmente são empregadas diferentes espécies de Acacia no tratamento das mais diversas patologias (Andrade et al., 2003). Dentre as atividades encontradas no gênero, tem havido vários relatos sobre atividade antibacteriana porem nenhuma citação para a espécie em estudo. Desta forma, o presente trabalho objetivou verificar o efeito dos extratos das flores desta planta sobre o crescimento de Staphylococcus aureus (ATCC 6538), Staphylococcus epidermidis (ATCC
1228), Escherichia coli (ATCC 11229) e Pseudomonas aeruginosa (ATCC 27853).

\section{MATERIAL E MÉTODOS}

\section{Material vegetal}

Flores da A. podalyriifolia A. Cunn. foram coletadas em Curitiba, entre os meses de Junho e Agosto de 2002. O material foi identificado pelo botânico Gert Hatschbach do Museu Botânico Municipal de Curitiba e uma amostra foi herbarizada no mesmo local sob o número 268.219.

\section{Triagem fitoquímica}

A triagem fitoquímica foi realizada no extrato 
Tabela 1. Inibição do crescimento bacteriano com extrato etanólico bruto (EEB), fração diclorometano de EEB (FDCM) e a fração acetato de etila de EEB (FAE) de A. podalyriifolia

\begin{tabular}{cccccc}
\hline & \multicolumn{5}{c}{ Zona de inibição de crescimento (mm de diâmetro) } \\
\hline Extrato/Fração & Dose $(\mu \mathrm{g} /$ disco & S. aureus & S. epidermidis & E. coli & P. aeruginosa \\
\hline \multirow{5}{*}{ EEB } & 1000 & 9 & 21 & - & - \\
& 500 & - & 15 & - & - \\
& 250 & - & - & - & - \\
\hline \multirow{5}{*}{ FDCM } & 125 & - & - & - & - \\
& 1000 & - & 10 & - & - \\
& 500 & - & - & - & - \\
\hline \multirow{5}{*}{ FAE } & 250 & - & - & - & - \\
& 125 & - & - & - & - \\
& 1000 & 13 & 24 & - & - \\
& 500 & - & 20 & - & - \\
\hline
\end{tabular}

etanólico bruto e nas frações obtidas por partição, conforme descrito no item "Preparo dos Extratos Vegetais". Os reativos utilizados foram descritos por Moreira (1979). Os grupos químicos testados foram: antocianos, saponinas, leucoantocianos, fenóis, flavonóides, taninos, antraquinonas, cumarinas, alcalóides e triterpenos/ esteróides.

\section{Preparo dos extratos vegetais}

Flores secas $(150 \mathrm{~g})$ de A. podalyriifolia foram extraídas com etanol em ebulição sob refluxo ( 5 vezes de 20 min. cada). O material foi filtrado e o filtrado foi concentrado em evaporador rotatório sob pressão reduzida, à temperatura de até $50^{\circ} \mathrm{C}$, até um volume final de $100 \mathrm{~mL}$ o qual foi mantido em geladeira por $15 \mathrm{~h}$ (durante a noite) e então centrifugado. O resíduo foi desprezado, obtendose o Extrato Etanólico Bruto (EEB). A $50 \mathrm{~mL}$ de EEB foram adicionados $100 \mathrm{ml}$ de água destilada. $\mathrm{O}$ extrato hidroalcoólico resultante $(150 \mathrm{~mL})$ foi desengordurado por partição com n-hexano em funil de separação até a fase hexânica apresentar-se incolor. A fase hidroalcoólica resultante do processo anterior foi, então, particionada com diclorometano em funil de separação até que a fase diclorometano se apresentasse incolor, resultando na Fração DiCloroMetano (FDCM). Em seguida procedeuse o particionamento da fase hidroalcoólica remanescente com acetato de etila em funil de separação, até que a fase acetato de etila se apresentasse incolor, resultando na Fração Acetato de Etila (FAE) (Kerber; Silva, 1993).

\section{Avaliação da Atividade Antibacteriana}

Para a avaliação da atividade antibacteriana dos extratos e frações das flores de A. podalyriifolia foi utilizado o método da difusão em gel (Smânia et al., 1995; Ulubelen et al., 2000).

O Extrato etanólico bruto (EEB), a fração diclorometano (FDCM) e a fração acetato de etila (FAE) foram esterilizados por filtração através de membranas (Millex ${ }^{\circledR}$ ), com poro de $0,22 \mu \mathrm{m}$ e adicionados em discos de papel filtro de $6 \mathrm{~mm}$ de diâmetro estéreis, nas concentrações de 1000, 500, 250 e $125 \mu \mathrm{g} /$ disco.

A atividade inibitória do crescimento de Staphylococcus aureus (ATCC 6538), Staphylococcus epidermidis (ATCC 1228), Escherichia coli (ATCC 11229) e Pseudomonas aeruginosa (ATCC 27853) foi verificada pela formação de halo de inibição do crescimento ao redor dos discos.

Foram utilizados, um disco de cloranfenicol $(30 \mu \mathrm{g})$ como controle positivo de inibição e discos impregnados com os solventes, como controle de inibição dos solventes. Todos os testes foram realizados em triplicata e a incubação foi de $24 \mathrm{~h} \mathrm{a} 35^{\circ} \mathrm{C}$.

\section{RESULTADOS}

A triagem fitoquímica do extrato etanólico bruto (EEB) das flores de A. podalyriifolia e de suas frações diclorometano (FDCM) e Acetato de Etila (FAE) indicou a presença de fenóis e flavonóides em todo o material testado. Os dados relativos à formação de halo de inibição de crescimento das cepas testadas frente as diferentes concentrações dos extrativos vegetais utilizados estão descritos na tabela 1.

\section{DISCUSSÃO}

$\mathrm{Na}$ avaliação da atividade antibacteriana do extrato etanólico bruto das flores de A. podalyriifolia e de suas frações ficou demonstrado o potencial antibacteriano dos mesmos sobre as cepas gram positivo (S. aureus e $S$. epidermidis). O mesmo não foi evidenciado com as cepas gram negativo (P. aeruginosa e $E$. coli). Compostos flavonoídicos foram relacionados à atividade antibacteriana de Ocimum basilicum (Anton, 
1988) e de Psidium guajava (Grovesnor; Supriono; Gray, 1995). Como foi verificada a presença de compostos flavonoídicos nos extratos testados os mesmos podem também estar envolvidos na atividade encontrada. Embora, dentre as cepas testadas, a maior atividade foi verificada contra $S$. epidermides, bactéria não nociva, ao homem, também foi verificada atividade contra $S$. aureus, em menor intensidade. Este resultado indica a necessidade de estudos futuros com um maior número de cepas bacterianas e também com uma variedade maior de bactérias. $\mathrm{O}$ fato de ter sido verificado atividade com apenas $125 \mu \mathrm{g} /$ disco para uma fração de extrato onde existe uma grande quantidade de substâncias, corrobora o forte potencial antibacteriano uma vez que o antibiótico de referência (cloranfenicol) é usado de forma pura na concentração de $30 \mu \mathrm{g} /$ disco.

\section{AGRADECIMENTOS}

Agradecemos ao botânico Gert Hatschbach do Museu Botânico Municipal da Prefeitura de Curitiba (MBM), pela identificação da espécie vegetal.

\section{REFERÊNCIAS}

Andrade CA, Peitz C, Silva VC, Miguel MD, Miguel OG, Kerber VA 2003. Revisão do gênero Acácia - Atividades biológicas e presença de fenóis derivados do núcleo flavânico. Visão Acadêmica 4: 47-56.

Anton R 1988. Flavonoids and tradicional medicine. In: Cody E, Harborne JR, Beretz A (Orgs.) Plant flavonoids in biology and medicine II. Progress in clinical and bilogical reserch, 280, Allan R. Liss, New York, 423-439, apud Grovesnor PW, Supriono A, Gray DO 1995. Medicinal Plants from Riau Province, Sumatra, Indonésia. Part. 2: antibacterial and antifungal activity. J Ethnopharmacol 45: 97-111.

Burkart A. 1979. Flora ilustrada catarinense. As Plantas Leguminosas Mimosoideas. Itajaí: Herbário Barbosa Rodrigues.

Grovesnor PW, Supriono A, Gray DO 1995. Medicinal plants from Riau Province, Sumatra, Indonésia. Part. 2: antibacterial and antifungal activity. JEthnopharmacol 45: 97-111.

Kerber VA, Silva GAAB 1993. Flavonoides de Acacia longifolia (Andr) Willd-Leguminosae-Mimosoidae. Rev Bras Farm 74: 16-18.

Moreira EA 1979. Contribuição ao estudo fitoquímico de Lobelia hassleri A. Zahlb e Lobelia stellfeladii R. Braga. Campanulaceae. Tribuna Farmacêutica 5: 1339.

Smânia AJr, Delle Monache F, Smania EFA, Gil ML, Bencherit LC, Cruz FS 1995. Antibacterial activity of a substance produced by fungus Pycnoporus sanguineus (Fr.) Murr. J Ethnopharmacol 45: 177-181.

Ulubelen A, Öksüz S, Bozok-Johansson C, Celik C, Voelter W 2000. Antibacterial diterpenes from the roots of Salvia viridis. Planta Med 66: 458-462.

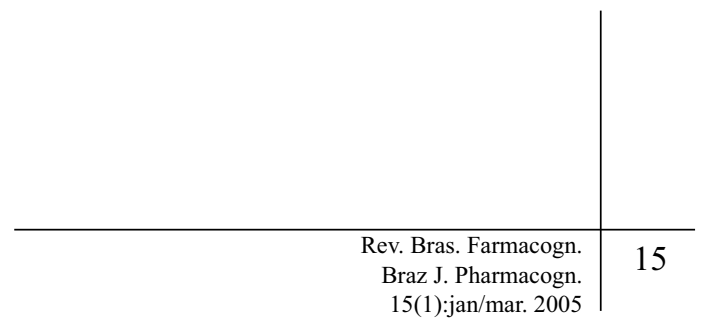

